\title{
How Did Order-Flow Impact Bond Prices During the European Sovereign Debt Crisis?
}

\author{
Zhongguo Lin ${ }^{\mathrm{a}}$, Philip A. Hamill ${ }^{\mathrm{b}}$, Youwei Li ${ }^{\mathrm{c}, 1}$, , Zhuowei Sun ${ }^{\mathrm{d}}$, James Waterworth \\ ${ }^{a}$ College of Management and Economics, Tianjin University, China. \\ ${ }^{\mathrm{b}}$ Abu Dhabi University, Abu Dhabi, UAE. \\ ${ }^{\mathrm{c}}$ Hull University Business School, University of Hull, Hull, UK. \\ ${ }^{\mathrm{d}}$ Financial Conduct Authority, London, UK. \\ 'School of Management, Queen's University Belfast, UK.
}

\begin{tabular}{|c|c|}
\hline ARTICLE INFO & ABSTRACT \\
\hline Article history: & $\begin{array}{l}\text { The impact of trades on price dynamics in the European } \\
\text { sovereign debt markets is of significant importance to policy }\end{array}$ \\
\hline$X X X X X X X X$ & $\begin{array}{l}\text { makers and market participants. This paper uses high-frequency } \\
\text { quote and transaction data from the MTS European sovereign bond }\end{array}$ \\
\hline JEL classif & inter-dealer platform to investigate price-order-flow dynamics from \\
\hline G01 & July 2005 until December 2011 for Germany, France, Portugal, Italy, \\
\hline G23 & Ireland, Spain and Greece. We find that order-flow had a larger impact \\
\hline $\mathrm{G} 24$ & $\begin{array}{l}\text { on quote revision in a relatively low-intensity trading environment } \\
\text { than in a relatively high-intensity trading environment implying that } \\
\text { informed traders should only execute in low-intensity trading } \\
\text { environments when they value immediacy over discretion. }\end{array}$ \\
\hline Keywords: & analysis is consistent with the limited prior literature for European \\
\hline Order-flow & debt markets. Our analysis indicates that this relationship persists \\
\hline Price impact & during turbulent market conditions. Also, we find that the impact of \\
\hline Trading intensity & order-flow on subsequent trades was larger during periods of high- \\
\hline Sovereign Bonds & $\begin{array}{l}\text { trading intensity implying that market participants use order splitting } \\
\text { trading strategies. }\end{array}$ \\
\hline
\end{tabular}

Corresponding author: Youwei Li (Youwei.li@ hull.ac.uk). Emails: Zhongguo Lin (lzg2011@tju.edu.cn), Philip Hamill (pa.hamill2@ gmail.com), Zhuowei Sun

(Zhuowei.Sun@fca.org.uk), and James Waterworth (jwaterworth02@qub.ac.uk). Acknowledgements: The authors sincerely acknowledge the financial support from the National Natural Science Foundation of China (No. 71571197, 71601140 and 71790594) and Tianjin Philosophy and Social Science Planning Project (No. TJYY16-005Q), as well as the financial support from China Scholarship Council. 


\section{Introduction}

Executing an order is expensive. By aggressing a quote or limit-order the price taker must pay the bid-ask spread for immediacy, as well as risk exposing valuable information and moving the price in the direction of their trading. In a market like Mercato dei Titoli di Stato (MTS), where the liquidity and transactions costs are visible to market participants, other low-visible measures of market quality and liquidity are important such as market impact, price trend and timing risk. Cheung, de Jong and Rindi (2005) also analyse MTS high-frequency data from January 2001 until May 2002. They investigate how trades are absorbed during periods of highand low- intensity trading. Predictions from the literature on the impact of trades conditional upon trading intensity is ambiguous. A number of papers argue that informed market participants want to trade as much as possible without being detected. Consequently, they trade during high-intensity trading periods when liquidity traders are active. This logic implies that an unexpected trade during a high-intensity trading period would have a larger impact on price (Kyle, 1985; Easley and O'Hara, 1992). Conversely, short-selling constraints may lead to a decrease in the probability of a market maker facing an informed trader trading on negative information implying that an unexpected trade during a low-intensity trading period would instead have a larger impact on price (Diamond and Verrechia, 1987). Recent theoretical and empirical analysis describes the role of order-splitting strategies and distinguishes between informed and less informed investors as they seek to optimise trading strategies. Informed investors use order-splitting strategies to slow the public revelation of private information to increase profits by minimize trading costs. Less informed investors also rely on order-splitting to minimize trading costs for hedging and portfolio rebalancing (O'Hara, 2015; Choi, Larsen and Seppi, 2019). The specific aim of this paper is to provide a comprehensive analysis of European sovereign bond markets through a period of crisis to evaluate the price-order-flow relationship conditional upon varying levels of trading intensity and to investigate if there is evidence of order-splitting.

To investigate this issue empirically an analysis of the price process is needed which requires the simultaneous modelling of price and order-flow dynamics, taking trading intensity into account. Dufour and Engle (2000) introduce an approach for testing and assessing the role played by the waiting time between consecutive transactions in the process of price formation. For US stock market data they find that trades had most impact on price during more active market periods. Cohen and Shin (2003) conduct a comparable analysis for the US Treasury 
market. They divide their dataset into days with and without news announcements, and find that the effect of trades on returns was higher on announcement days. However, they do not explicitly include intraday trading intensity in their analysis. In contrast when intra-daily data is incorporated into the analysis, Cheung et al. (2005) report that the impact of a trade in a relatively low-trading intensive environment had a larger impact on price than in a relatively high-trading intensive environment. This paper contributes to the literature examining priceorder-flow dynamics on European sovereign bond markets. It analyses (MTS) high frequency data for French, German, Greek, Irish, Italian, Portuguese and Spanish government bonds from 1 July 2005 to 31 December 2011 which captures the impact of the global financial crisis and European sovereign debt crisis. Three distinct periods over our sample period are classified as calm, global financial crisis and European sovereign debt crisis to examine the effect of trades on price. A modified version of the methodology proposed by Dufour and Engle (2000) is used to investigate this relationship. We evaluate the interaction between returns and order-flow and assess whether trades were better absorbed by market-makers in periods of high- or low-trading intensity. We find that for the majority of countries in the majority of periods there was an instantaneous upward (downward) price movement following a buy (sell) trade. We also report that order-flow had a larger impact on quote revision during relatively low-intensity trading periods than in the relatively high-intensity trading periods. This finding supports the shortselling constraints theory posited by Diamond and Verrechia (1987) which implies that price impact on the MTS market can be minimised by splitting large orders into multiple smaller orders and dripping them into the market over a longer period, ideally during busier trading conditions. Further, we find that order-flows were strongly correlated and the impact of orderflow on subsequent trades was larger during periods of high-trading intensity. This implies that market participants use order splitting as part of their trading strategy and that there are multiple informed traders acting on the same private information.

The rest of the paper is organized as follows: Section 2 provides a detailed explanation of the data and how it was constructed; section 3 outlines the methodology employed to model two dynamic equations for price changes and signed quantities; section 4 reports the empirical results, while section 5 summarizes the key findings from our analysis and suggests an important area for further research given recent regulatory changes. 


\section{European sovereign bond market data}

The MTS interdealer platform data covers every transaction for French, German, Greek, Irish, Italian, Portuguese and Spanish government bonds being traded on the MTS platform from 1 July 2005 to 31 December 2011. For each instrument included in the study the limit-order book is available in aggregate format with millisecond timestamp. Specifically, the total aggregated volumes of the top three price levels of the limit-order book as well as any changes such as new quotes and orders, updates, and cancellations. Similarly, trades are recorded with a timestamp accurate to one millisecond, and the direction of the trade (buy or sell) is recorded.

For the benchmark liquidity analysis, to give an accurate picture of the market and to avoid yield curve effects, we conduct the analysis on the current benchmark instrument for three different durations: short, medium, and long. As per Dunne, Moore and Portes (2007), and in accordance with industry standard, the short-, medium- and long-term maturity buckets are defined as 1 to 3.5 years, 3.5 to 6.5 years and 6.5 to 13.5 years respectively. When selecting instruments for the benchmark analysis we select the most recently issued instrument within each maturity bucket. The larger economies of France, Germany and Italy have a regular issuance of debt at all maturities. Accordingly, we roll the benchmark instruments on the day of issuance or the first date where the instrument is available for trading on the MTS platform. The smaller economies of Greece, Ireland, Portugal and Spain issue debt less frequently, especially during the crisis periods. As such, in some instances the situation arises where it is not possible to simply roll to a newly issued benchmark.

\section{INSERT TABLE 1 ABOUT HERE}

Formally, to select the benchmark bond for a given maturity bucket, we use the following criteria. For each maturity bucket, starting at 1 July 2005, select the most recently issued instrument with maturity fitting into said maturity bucket. This instrument is the benchmark instrument until either a) a new instrument is issued that fits into the maturity bucket, or b) the current instrument leaves the maturity bucket. In the case of b), we assume that there has not been a new instrument issued that fits into the maturity bucket, in which case we select the most recently issued instrument in the maturity bucket. If none exists, we wait until a) a new bond is issued that fits into the maturity bucket, or b) an existing bond moves into the maturity bucket. It happens for Ireland during the sample period that there is one instance for each short and medium benchmark where no bond fits the maturity bucket. It is not possible to calculate 
metrics during these periods. It is not always possible to find benchmark instruments being quoted on both EuroMTS and MTS Domestic Markets for the short and medium maturities. Consequently, the analysis on the long maturity benchmarks is conducted on the aggregate order book across both market segments, and the analysis on the short and medium maturities is limited to the MTS Domestic Markets segment only. Table 1 provides an overview of the benchmark bonds in the dataset for short, medium and long duration for each country.

Since several significant events took place during our study period, in addition, we divided the full sample into three sub-periods:

- $\quad$ Calm Period (PRE): 1st July 2005 to 14th July 2007.

- Global Financial Crisis (GFC): 15th July 2007 to 15th January 2009. From July 2007, banks in the UK stopped lending to each other due to market fears that counterparts were exposed to the emerging US sub-prime crisis. In July, Bear Sterns informed investors that they would get little, if any, money back from two hedge funds with large holdings of sub-prime mortgages. LIBOR rates spiked. Following a BBC report on the 13th September, Northern Rock experienced a bank-run on the 14th. It was subsequently nationalised on 22nd February 2008.

- $\quad$ European Sovereign Debt Crisis: 16th January 2009 to 7th May 2010. On 15th January 2009, the Irish government announced that it would nationalise Anglo Irish Bank. Fall 2009 Greece's budget was revised highlighting that the deficit for that year would be significantly higher than previously predicted. On 2nd May 2010 the EU endorsed the IMF announced an $€ 85$ bn first European financial rescue plan for Greece. From 8th May 2010 to 31st December 2011, problems persisted and Greece and a second rescue package was negotiated with Greece in 2011. On 28th November 2010 the Trokia (European Commission, European Central Bank and International Monetary Fund) agreed an €85bn bailout deal with the Irish Government. On 5th May 2011, Portugal agreed with the EU and IMF on a $€ 78 \mathrm{bn}$ bailout in exchange for an austerity programme. Pelizzon, Subrahmanyam, Tomio and Uno (2016) show that for Italian sovereign bonds it was not until the start of 2012 that ECB interventions (the Long-Term Refinancing Operations: LTRO) diminished the impact of credit risk which suggests it wasn't until this point that the crisis period ended economically.

\section{Methodology}


Price impact is modelled by taking order-flow dynamics and trading intensity into account using the VAR model proposed by Dufour and Engle (2000). The model is a system of two dynamic equations. One for price changes (returns) and one for signed quantities with lagged values of both variables as explanatory variables. This model facilitates the analysis of the interaction between order-flow and returns in the form of impulse responses of a shock (an unexpected trade) to the trading process. The main advantage of this model is the dynamic setup between order-flow and price return that is important because participants on the MTS trading platforms can continuously view live quotes and are able to extract information from the live quote updates. Therefore, the process of market making not only depends on the concurrent price and trade but also on the previous changes in price and order-flow. Lagged traded quantity is also important as the MTS trading system allows the splitting of orders and it is likely that the observed order book is the drip quantity instead of the total (block) quantity.

Following Dufour and Engle (2000), we make the coefficients a function of trading intensity defined as the reciprocal of the number of minutes between two trades with coefficients also depending on the location of the trade, i.e. whether the trade occurred on EuroMTS or the MTS Domestic Markets. The subscript $t$ denotes sequential transaction time, either trade or quote update. The model is as follows:

$$
\begin{aligned}
r_{t}=\bar{\alpha}^{r}+\sum_{i=1}^{K}\left(\bar{\beta}_{i}^{r}+\bar{z}_{i}^{r} \ln \left(T_{t-i}\right)\right) r_{t-i} \\
\quad+\sum_{i=0}^{K}\left(\bar{\gamma}_{i}^{r}+\bar{\delta}_{i}^{r} D_{t-i}+\bar{\tau}_{i}^{r} \ln \left(T_{t-i}\right)\right) Q_{t-i}+\varepsilon_{1, t} \\
Q_{t}=\bar{\alpha}^{Q}+\sum_{i=1}^{K}\left(\bar{\beta}_{i}^{Q}+\bar{z}_{i}^{Q} \ln \left(T_{t-i}\right)\right) r_{t-i} \\
\quad+\sum_{i=1}^{K}\left(\bar{\gamma}_{i}^{Q}+\bar{\delta}_{i}^{Q} D_{t-i}+\bar{\tau}_{i}^{Q} \ln \left(T_{t-i}\right)\right) Q_{t-i}+\varepsilon_{2, t}
\end{aligned}
$$

where $r_{t}=10,000 \ln \left(P_{t} / P_{t-1}\right)$ is the change in the logarithm of mid-quote prices, $Q_{t}$ is the signed trade quantity in millions, $T_{t}$ is the time in minutes between a trade and the previous trade ( 0 for quotes), $D_{t}$ is market dummy variable equal to 1 if the trade was on EuroMTS and 0 if it was on the MTS Domestic Markets, $\mathrm{K}$ is the number of lags. Equation (1) primarily analyses the effect of trades on quote revision, while also accounting for lagged returns.

In the returns equation:

- The $\gamma_{i}^{r}$ parameters reflect the interaction between signed trade quantity and return.

- The $\delta_{i}^{r}$ parameters account for market sector in the interaction between signed trade quantity and return.

- The $\tau_{i}^{r}$ parameters account for trading intensity in the interaction between signed trade quantity and return. 
For the quantity equation:

- The $\gamma_{i}^{Q}$ parameters account for lagged signed trade quantity.

- The $\delta_{i}^{Q}$ parameters account for market sector.

- The $\tau_{\mathrm{i}}^{\mathrm{Q}}$ parameters account for trading intensity.

The key parameters for discussion are $\bar{\gamma}_{i}^{r}, \bar{\delta}_{i}^{r}$ and $\bar{\tau}_{i}^{r}$. Given the dependent variable is $r_{t}=$ $10,000 \ln \left(\mathrm{P}_{\mathrm{t}} / \mathrm{P}_{\mathrm{t}-1}\right)$ the implications of the results of the returns regressions are as follows:

- The expected instantaneous price reaction of a one million buy trade on MTS Domestic Markets is $\gamma_{0}^{r}$ basis points.

- The expected instantaneous price reaction of a one million buy trade on EuroMTS is $\gamma_{0}^{r}+$ $\delta_{0}^{r}$ basis points.

- The expected instantaneous price reaction of a one million buy trade on MTS Domestic Markets given a duration $\ln \left(\tau^{*}\right)$ is given by $\gamma_{0}^{r}+\tau_{0}^{r} \ln \left(\tau^{*}\right)$.

- The expected instantaneous price reaction of a one million buy trade on EuroMTS given a duration $\ln \left(\tau^{*}\right)$ is given by $\gamma_{0}^{r}+\delta_{0}^{r}+\tau_{0}^{r} \ln \left(\tau^{*}\right)$.

\section{Empirical results}




\subsection{Impact of trading on prices}

Table 2 reports the results for the returns model equation 1. The $\gamma_{\mathrm{i}}^{\mathrm{r}}$ parameters, reported in panel A, reflect the interaction between signed trade quantity and return. Looking first at the core countries (Germany and France) in the calm period, the $\gamma_{0}^{\mathrm{r}}$ parameter has a positive (0.0393), but insignificant coefficient for the German benchmark ${ }^{2}$. A positive coefficient indicates an instantaneous upward (downward) price movement following a buy (sell) trade, which is consistent with Cheung et al. (2005). In contrast, the parameter (-0.4819) is negative and statistically significant for France which indicates that there was an instantaneous downward (upward) price movement following a buy (sell) trade which is at odds with our expectation. During the global financial crisis, the coefficients for both France (0.1675) and Germany (0.0287) were positive and significant whereas for the European sovereign debt crisis only France had a significant positive coefficient (0.0755), while Germany was insignificant. For the semi-core countries (Italy and Spain) during the calm period, the $\gamma_{0}^{\mathrm{r}}$ parameter is negative for Italy $(-0.2175)$ but positive for Spain (0.0109) with both being statistically significant, while both are statistically insignificant during global financial crisis. During the European sovereign debt crisis both significantly positive with respective coefficients of 0.0466 and 0.1484 . Out of the three peripheral countries (Greece, Ireland and Portugal) only Greece experiences a significant positive reaction during the calm period. None of the peripheral countries have significant coefficients during the global financial crisis. During the European sovereign debt crisis Greece has a significant negative coefficient (-0.1987), while Ireland has a significant positive coefficient of 0.7864 which is the largest contemporaneous, or lagged, point estimate for all countries. Lagged values are generally positive across all countries and periods, although only a minority are significant. The positive values are consistent with the findings of Cheung et al. (2005), and can be attributed to active position building.

\section{INSERT TABLE 2 and 3 ABOUT HERE}

As above, the expected instantaneous price reaction of a one million buy trade on the domestic platform is $\gamma_{0}^{r}$ basis points. Additionally, the values for the expected instantaneous price reaction of a five million buy trade on MTS Domestic Markets and EuroMTS have been calculated and are reported in Table 4. Of the 21 variables reflecting the price reaction on MTS Domestic Markets, there are 15 positive values and 6 negative values indicating that on MTS Domestic Markets for the majority of countries in the majority of periods there was an instantaneous upward (downward) price movement following a buy (sell) trade. The $\delta_{\mathrm{i}}^{\mathrm{r}}$ parameters reported in panel B account for market sector in the interaction between

\footnotetext{
${ }^{2}$ See Antonakakis and Vergos (2013) and Yan, Hamill, Li, Waterworth and Vigne (2018) for justification and analysis of countries in our study categorized as being core, periphery or semi-core.
} 
signed trade quantity and return. Recall that the dummy variable $\mathrm{D}_{\mathrm{t}-\mathrm{i}}$ is set equal to 1 for trades on EuroMTS, and 0 for trades on MTS Domestic Markets. During the calm period $\delta_{0}^{\mathrm{r}}$ is significantly positive for France (0.6197) and Spain (0.0150), and also for France (0.0954), Spain (0.1425), Greece (0.6112) and Portugal (0.9844) during the sovereign debt crisis. This implies that a trade on the EuroMTS had a significantly larger instantaneous impact on price relative to the same trade on MTS Domestic Markets. In contrast it is significantly less for Germany (-0.0343) during the Global Financial Crisis, and also for Greece (-0.0109) and Ireland (-0.0311) during calm periods which implies a lower instantaneous impact on price relative to the same trade on the MTS domestic market. These results should be viewed in context with Figure 1, which shows that there was a marked decrease in the number of trades on EuroMTS compared to MTS Domestic Markets during the European sovereign debt crisis. Taken together these results highlight variation in the magnitude of coefficient estimates across countries with some significant negative values indicating structural differences in how markets absorb trades which provides guidance for further country specific research.

\section{INSERT FIGURE 1 ABOUT HERE}

The $\tau_{i}^{r}$ parameters account for trading intensity in the interaction between signed trade quantity and return. During the global financial crisis, the $\tau_{0}^{\mathrm{r}}$ parameter is significantly positive for Germany $(0.0120)$, France (0.0680), and Portugal (0.0062). Likewise, it is significant for Italy (0.0888) and Ireland (0.0049) during the calm period, and also European sovereign debt crisis for Germany (0.0233), Italy (0.0096) and Greece (0.3449). Positive values imply that the larger the quantity being traded the larger the instantaneous price reaction, and that the reaction was strongest when trading intensity was low. Knowledge of the impact that trade execution has on price is particularly relevant for informed traders who are trying to minimise the price impact of trading, as they may want to minimise price impact in order to conceal privileged information. The logic of using order-splitting to minimise price impact to increase profits for informed investors and minimise trading costs for less informed investors such as index mutual funds and relatively more passive pension and insurance companies, underpins the model of Choi et al. (2019). This result implies that price impact on the MTS market can be minimised by splitting large orders into multiple smaller orders and dripping them into the market over a longer period. This strategy would however expose market participants to the risk of an adverse price movement. They may prefer to execute the whole volume in one order at the best price regardless of the resulting price impact. This result is consistent with Cheung et al. (2005) who also find that the impact of a trade in a relatively low intensity trading environment had a larger impact on price for the MTS market in 200102. However, it differs to the finding of Dufour and Engle (2000) in their analysis of stock markets.

\subsection{Quantity equation}


Table 4 reports the results for the quantity equation regression. The $\gamma_{i}^{r}$ parameters, panel A, account for lagged signed trade quantity. The $\gamma_{1}^{\mathrm{Q}}$ parameters in the first column of results are positive and statistically significant for all countries for all periods. This indicates that a buy (sell) trade was likely to be followed by a buy (sell) trade. The lagged values of $\gamma_{i}^{Q}$ in the second column of data are similarly positive and significant in all instances except for $\gamma_{2}^{\mathrm{Q}}$ Ireland in the pre-crisis calm period. Order splitting to minimise price impact is one potential reason for the finding that trades are likely followed by trades in the same direction. This is consistent with the discussion of the $\tau_{0}^{\mathrm{r}}$ parameter results in the previous section. Executing large orders has a larger impact on price; market participants can minimise this impact by splitting large orders into smaller orders and dripping them into the market in the hope of preserving privileged information. Another potential reason is that when private events happen the privileged information becomes available to multiple market participants and they act on it within a short time frame until the opportunity no longer exists.

\section{INSERT TABLE 4 ABOUT HERE}

The $\delta_{i}^{r}$ parameters account for market sector. This effect was strongest on MTS Domestic Markets for Germany where the $\delta_{1}^{Q}$ parameters are negative and significant across all periods. This implies that lagged trades on EuroMTS had a smaller instantaneous impact on current trades relative to the same trade on MTS Domestic Markets. During the calm period, the $\delta_{1}^{Q}$ parameters are negative for France and Portugal, but only statistically significant for Portugal. It is positive for the remaining four countries. During the global financial crisis, the $\delta_{1}^{\mathrm{Q}}$ parameters are negative for Greece, Ireland and Portugal, positive for Italy, France and Spain. All are statistically significant. During the European sovereign debt crisis, the $\delta_{1}^{Q}$ parameters are positive and significant for all countries other than Germany. This implies that lagged trades on EuroMTS had a larger instantaneous impact on current trades relative to the same trade on MTS Domestic Markets. There is no consistent pattern across the additional lagged variables, implying there was not one market segment that increased this effect. The $\tau_{i}^{r}$ parameters account for trading intensity. The $\tau_{1}^{\mathrm{r}}$ parameters, panel $\mathrm{C}$ first column of results, are significantly negative for all countries for all periods except Germany during the global financial crisis, which is insignificant, and Portugal during the European sovereign debt crisis which is positive and significant $(0.0027)$. Taken in context with the generally positive $\delta_{1}^{Q}$ parameters, the likelihood that a trade was followed by a trade of the same direction decreased as the time between the trades increased. Again, this is consistent with the practice of order splitting and multiple informed traders acting on the same private information.

Overall, this paper provides a comprehensive empirical analysis for European sovereign bonds markets. While we argue that on balance a number of findings emerge there is also some heterogeneity in our 
results at the individual country levels. For example, in section 2.1. we highlight that in the returns equation there is an anomalous significant negative coefficient on the $\gamma_{\mathrm{i}}^{\mathrm{r}}$ parameter for France. We hope this will motivate further analysis at the country level. Also, while our findings are consistent with Cheung et al. (2005) for European sovereign bond markets they contrast with equity markets. Given the theoretical model of Choi et al. (2019) there is scope for additional research in this area given the dearth of theoretical and empirical analysis.

\section{Conclusion}

This paper uses high-frequency quote and transaction data from the MTS European sovereign bond inter-dealer platform to investigate the price-order-flow dynamics from July 2005 to December 2011 for Germany, France, Portugal, Italy, Ireland and Spain, Greece. We find that order-flow had a larger impact on quote revision in a relatively low-intensity trading environment than in a relatively high intensity trading environment implying that informed traders should only execute in low-intensity trading environments when they value immediacy over discretion. Further, we find that order-flows were strongly correlated, and the impact of order-flow on subsequent trades was larger during periods of high trading intensity. Taken together with the first main result, we conclude that market participants on the MTS market use order-splitting as part of their trading strategy to minimise price impact, and that there are multiple informed traders acting on the same private information. To our knowledge Cheung et al. (2005) is the only other paper to provide a comparable analysis for the European sovereign bond market. Their dataset encompasses Italian, French, German and Belgian government bonds traded on MTS from January 2001 until May 2002. They report that the impact of a trade in a relatively low trading intensity environment has a larger impact on price than in a relatively high intensity environment. Our analysis shows that this result holds during the global financial crisis and European sovereign debt crisis.

There is significant scope to extend this analysis to inform policy. European capital markets were subject to updated Markets in Financial Instruments Regulation (MiFIR) and the accompanying Markets in Financial Instruments Directive (MiFID II) from $3^{\text {rd }}$ January 2018 that regulates both investment firms and trading venues. An obvious extension of this paper would be to repeat our analysis to make use of quasi-experimental research design to assess the impact of these regulatory innovations. 


\section{References}

Antonakakis, N., and Vergos, K., 2013. Sovereign bond yield spillovers in the euro zone during the financial and debt crisis. Journal of International Financial Markets, Institutions and Money 26, 258-272.

Cheung, Y., de Jong, F., and Rindi, B., 2005. Trading European sovereign bonds: the microstructure of the MTS trading platforms. Working Paper Series 0432, European Central Bank.

Choi, J. H., Larsen, k., and Seppi, D. J., 2019. Information and trading targets in a dynamic market equilibrium. Journal of Financial Economics, 132(3), 22-49.

Cohen, B., and Shin, H.S., 2003. Positive feedback trading under stress: evidence from the US treasury securities market. Working Paper, LSE.

Diamond, D., and Verecchia, R., 1987. Constraints on short selling and asset price adjustment to private information. Journal of Financial Economics 18, 277-311.

Dufour, A., and Engle, R.F., 2000. Time and the price impact of a trade. Journal of Finance 55(6), $2467-$ 2498.

Dunne, P.G., Moore, M.J., and Portes, R., 2007. Benchmark status in fixed-income asset markets. Journal of Business Finance and Accounting 34, 1615-1634.

Easley, D., and O'Hara, M., 1992. Time and the process of security price adjustment. Journal of Finance 47, 577-605.

Kyle, A., 1985. Continuous auction and insider trading. Econometrica 53, 1315-1336.

O’Hara, M., 2015. High frequency market microstructure. Journal of Financial Economics. 116(2), 257270.

Pelizzon, L., Subrahmanyam, M. G., Tomio, D., and Uno, J., 2016. Sovereign Credit Risk, Liquidity, and ECB Intervention: Deux ex Machina?, Journal of Financial Economics, Vol. 122 (1), pp. $86-115$.

Yan, W., Hamill. P. A., Li. Y, Waterworth, J. and Vigne, S. (2018) 'An Analysis of Liquidity Skewness for European Sovereign Bond Markets', Finance Research Letters. 26: 274-280. 
Table 1. European sovereign benchmark bonds

\begin{tabular}{|c|c|c|c|c|c|c|c|c|}
\hline $\begin{array}{l}\text { Country } \\
\text { (market) }\end{array}$ & Type & Ticker & Maturity & $\begin{array}{l}\text { Number of } \\
\text { bonds }\end{array}$ & $\begin{array}{l}\text { Avg } \\
\text { duration } \\
\text { (yrs) }\end{array}$ & $\begin{array}{l}\text { Avg } \\
\text { coupon } \\
(\%)\end{array}$ & $\begin{array}{l}\text { Avg daily } \\
\text { quote vol } \\
\text { (million } € \text { ) }\end{array}$ & $\begin{array}{l}\text { Avg daily } \\
\text { number of } \\
\text { trades } \\
\text { (abs num) }\end{array}$ \\
\hline France & BTA & BTNS & Short & 8 & 2.4 & 2.4 & 203 & 1.4 \\
\hline \multirow[t]{2}{*}{ (FRF) } & BTA & BTNS & Medium & 23 & 5.4 & 3.4 & 186 & 1.2 \\
\hline & OAT & FRTR & Long & 30 & 10.6 & 4.7 & 363 & 2.6 \\
\hline Germany & DEM & BKO & Short & 28 & 2.0 & 2.2 & 133 & 0.5 \\
\hline \multirow[t]{2}{*}{ (GEM) } & DEM & OBL & Medium & 26 & 5.6 & 3.25 & 134 & 0.4 \\
\hline & DEM & DBR & Long & 39 & 10.1 & 4.25 & 290 & 2.0 \\
\hline Italy & BTP & BTPS & Short & 22 & 3.0 & 3.2 & 221 & 14.6 \\
\hline \multirow[t]{2}{*}{ (MTS) } & BTP & BTPS & Medium & 21 & 5.1 & 3.8 & 208 & 13.9 \\
\hline & BTP & BTPS & Long & 29 & 10.3 & 5.3 & 360 & 29.6 \\
\hline Greece & GGB & GGB & Short & 6 & 3.3 & 3.1 & 95 & 1.1 \\
\hline \multirow[t]{2}{*}{ (GGB) } & GGB & GGB & Medium & 9 & 5.3 & 4.3 & 118 & 1.2 \\
\hline & GGB & GGB & Long & 16 & 9.9 & 5.6 & 190 & 4.4 \\
\hline Ireland & IRL & IRISH & Short & 2 & 3.0 & 4.0 & 81 & 0.4 \\
\hline \multirow[t]{2}{*}{ (IRL) } & IRL & IRISH & Medium & 3 & 5.6 & 3.8 & 63 & 0.5 \\
\hline & IRL & IRISH & Long & 5 & 10.9 & 5.0 & 149 & 0.7 \\
\hline Portugal & PTE & PGB & Short & 3 & 3.3 & 3.0 & 139 & 2.9 \\
\hline \multirow[t]{2}{*}{ (PTE) } & PTE & PGB & Medium & 6 & 5.1 & 4.4 & 139 & 2.0 \\
\hline & PTE & PGB & Long & 14 & 10.3 & 5.1 & 263 & 3.6 \\
\hline Spain & BON & SPGB & Short & 6 & 3.1 & 3.0 & 170 & 1.6 \\
\hline \multirow[t]{2}{*}{ (ESP) } & BON & SPGB & Medium & 12 & 5.1 & 3.7 & 168 & 1.9 \\
\hline & OBE & SPGB & Long & 20 & 10.3 & 5.3 & 302 & 4.4 \\
\hline
\end{tabular}

Notes: This table contains reference information for the benchmark instruments of the seven countries included in the analysis. The first column details the country and the MTS Domestic Markets identifier. The second and third columns detail two important MTS market identifiers: the bond type and ticker, respectively. The maturity column details whether the bond type is short-, medium- or long-term, defined as 1 to 3.5 years, 3.5 to 6.5 years and 6.5 to 13.5 years respectively. Descriptice statistics include the number of bonds per category, the average duration in years, the average coupon in percentage of par, the average daily quote volume in millions of euro, and the average daily nunber of trades in absolute number. 
Table 2. Returns equation

Panel A: Returns equation: signed trade quantities, and market and signed trade quantities

\begin{tabular}{|c|c|c|c|c|c|c|c|c|c|}
\hline \multirow{8}{*}{ Germany } & \multirow{4}{*}{ Calm } & \multicolumn{4}{|c|}{ Signed trade quantities } & \multicolumn{4}{|c|}{ Market and signed trade quantities } \\
\hline & & $\gamma_{0}$ & $\gamma_{1}$ & $\gamma_{2}$ & $\gamma_{3}$ & $\delta_{0}$ & $\delta_{1}$ & $\delta_{2}$ & $\delta_{3}$ \\
\hline & & 0.0393 & 0.0150 & 0.0150 & 0.0107 & 0.0019 & -0.4292 & -0.0035 & 0.0035 \\
\hline & & {$[0.82]$} & {$[0.31]$} & {$[0.31]$} & {$[0.33]$} & {$[0.04]$} & {$[-8.95]$} & {$[-0.07]$} & {$[0.07]$} \\
\hline & Glob. fin. crisis & 0.0287 & 0.0338 & 0.0112 & 0.0181 & -0.0343 & -0.0175 & -0.0001 & -0.0022 \\
\hline & & {$[3.08]$} & {$[3.62]$} & [1.2] & {$[3.12]$} & {$[-3.68]$} & {$[-1.87]$} & {$[-0.01]$} & {$[-0.23]$} \\
\hline & Euro sov. debt & 0.0228 & 0.0093 & 0.0134 & 0.0095 & 0.0026 & -0.0123 & -0.0444 & -0.0012 \\
\hline & & [0.9] & {$[0.36]$} & {$[0.52]$} & {$[0.61]$} & {$[0.06]$} & {$[-0.28]$} & {$[-1.02]$} & {$[-0.03]$} \\
\hline \multirow[t]{6}{*}{ France } & Calm & -0.4819 & 0.5488 & 0.0284 & -0.0351 & 0.6197 & 1.0458 & -0.3467 & 0.0277 \\
\hline & & {$[-3.27]$} & {$[3.71]$} & [0.19] & {$[-0.33]$} & {$[3.52]$} & [5.94] & {$[-1.97]$} & {$[0.16]$} \\
\hline & Glob. fin. crisis & 0.1675 & - & -0.0266 & 0.0005 & -0.1650 & 0.9144 & -0.0468 & -0.1045 \\
\hline & & [2.47] & {$[-3.12]$} & [-0.39] & {$[0.01]$} & {$[-1.8]$} & {$[9.98]$} & {$[-0.51]$} & {$[-1.15]$} \\
\hline & Euro sov. debt & 0.0755 & 0.0110 & 0.0036 & 0.0157 & 0.0954 & 0.0556 & 0.0373 & 0.0145 \\
\hline & & {$[6.38]$} & {$[0.92]$} & {$[0.3]$} & {$[2.3]$} & [3.19] & {$[1.85]$} & [1.24] & {$[0.48]$} \\
\hline \multirow[t]{6}{*}{ Italy } & Calm & -0.2175 & 0.0223 & -0.0065 & 0.0099 & 0.0899 & 0.0256 & 0.0086 & -0.0996 \\
\hline & & {$[-4.96]$} & {$[0.51]$} & {$[-0.15]$} & {$[0.33]$} & {$[1.24]$} & {$[0.35]$} & [0.12] & {$[-1.37]$} \\
\hline & Glob. fin. crisis & 0.0115 & 0.0206 & 0.0423 & 0.0154 & -0.0027 & -0.0145 & -0.0166 & -0.0041 \\
\hline & & {$[0.44]$} & {$[0.78]$} & [1.61] & [0.9] & {$[-0.06]$} & {$[-0.30]$} & {$[-0.34]$} & {$[-0.09]$} \\
\hline & Euro sov. debt & 0.0466 & 0.0558 & 0.0260 & 0.0358 & 0.0053 & 0.0218 & -0.0025 & -0.0006 \\
\hline & & [11.01] & [13.12] & {$[6.09]$} & [15.22] & {$[0.37]$} & {$[1.50]$} & {$[-0.17]$} & {$[-0.04]$} \\
\hline \multirow[t]{6}{*}{ Spain } & Calm & 0.0109 & - & -0.0019 & -0.0040 & 0.0150 & 0.0049 & 0.0078 & 0.0018 \\
\hline & & {$[3.07]$} & {$[-1.50]$} & {$[-0.52]$} & {$[-2.05]$} & {$[2.83]$} & {$[0.93]$} & [1.47] & {$[0.33]$} \\
\hline & Glob. fin. crisis & -0.0022 & 0.0001 & 0.0031 & 0.0071 & 0.0174 & 0.0094 & 0.0018 & 0.0024 \\
\hline & & [-0.09] & {$[0.01]$} & {$[0.13]$} & {$[0.51]$} & {$[0.48]$} & {$[0.26]$} & {$[0.05]$} & {$[0.07]$} \\
\hline & Euro sov. debt & 0.1484 & 0.0227 & 0.0356 & 0.0283 & 0.1425 & 0.1106 & 0.0377 & 0.0875 \\
\hline & & [5.09] & {$[0.78]$} & [1.21] & [1.96] & {$[2.01]$} & {$[1.56]$} & {$[0.53]$} & [1.24] \\
\hline \multirow[t]{6}{*}{ Greece } & Calm & 0.0377 & 0.0139 & 0.0074 & 0.0026 & -0.0109 & -0.0069 & -0.0025 & -0.0016 \\
\hline & & [9.85] & {$[3.61]$} & [1.91] & {$[1.32]$} & {$[-2.6]$} & {$[-1.64]$} & {$[-0.6]$} & {$[-0.38]$} \\
\hline & Glob. fin. crisis & 0.0509 & 0.0353 & -0.0009 & 0.0103 & 0.0056 & -0.0154 & -0.0071 & 0.0022 \\
\hline & & {$[0.98]$} & {$[0.68]$} & {$[-0.02]$} & {$[0.38]$} & {$[0.09]$} & {$[-0.26]$} & {$[-0.12]$} & {$[0.04]$} \\
\hline & Euro sov. debt & -0.1987 & 0.0935 & 0.0676 & 0.0706 & 0.6112 & -0.3295 & -0.1367 & 0.0182 \\
\hline & & {$[-2.39]$} & [1.12] & {$[0.8]$} & [1.39] & {$[3.72]$} & {$[-2.01]$} & {$[-0.83]$} & [0.11] \\
\hline \multirow[t]{6}{*}{ Ireland } & Calm & 0.0126 & 0.0020 & 0.0119 & 0.0090 & -0.0311 & -0.0103 & -0.0018 & 0.0024 \\
\hline & & {$[1.25]$} & {$[0.2]$} & [1.15] & {$[1.41]$} & {$[-3.13]$} & {$[-1.02]$} & {$[-0.18]$} & {$[0.24]$} \\
\hline & Glob. fin. crisis & 0.0187 & 0.0038 & 0.0514 & 0.0668 & -0.0738 & 0.0285 & -0.0237 & -0.0272 \\
\hline & & {$[0.2]$} & {$[0.04]$} & {$[0.54]$} & {$[0.97]$} & {$[-0.74]$} & {$[0.28]$} & {$[-0.24]$} & {$[-0.27]$} \\
\hline & Euro sov. debt & 0.7864 & 0.0806 & 0.4543 & 0.2437 & 0.0907 & 0.0919 & 0.1245 & -0.1722 \\
\hline & & [1.97] & {$[0.2]$} & [1.09] & {$[1.27]$} & {$[0.16]$} & {$[0.17]$} & {$[0.22]$} & {$[-0.31]$} \\
\hline \multirow[t]{6}{*}{ Portugal } & Calm & 0.0074 & 0.0026 & 0.0026 & 0.0002 & -0.0032 & -0.0022 & -0.0055 & -0.0090 \\
\hline & & {$[0.66]$} & {$[0.23]$} & {$[0.23]$} & {$[0.03]$} & {$[-0.16]$} & {$[-0.11]$} & {$[-0.28]$} & {$[-0.45]$} \\
\hline & Glob. fin. crisis & -0.0051 & 0.0150 & 0.0025 & 0.0079 & 0.0030 & -0.0035 & 0.0026 & -0.0017 \\
\hline & & {$[-1.08]$} & [3.17] & {$[0.52]$} & {$[2.56]$} & {$[0.47]$} & {$[-0.55]$} & {$[0.41]$} & {$[-0.27]$} \\
\hline & Euro sov. debt & -0.0290 & 0.0024 & -0.0080 & 0.0628 & 0.9844 & 0.4126 & -0.0248 & -0.0857 \\
\hline & & {$[-0.18]$} & {$[0.01]$} & {$[-0.05]$} & {$[0.72]$} & {$[2.58]$} & {$[1.08]$} & {$[-0.06]$} & {$[-0.22]$} \\
\hline
\end{tabular}


Panel B: Returns equation: returns, and intensity and returns

\begin{tabular}{|c|c|c|c|c|c|c|c|}
\hline \multirow{8}{*}{ Germany } & \multirow{4}{*}{ Calm } & \multicolumn{3}{|c|}{ Returns } & \multicolumn{3}{|c|}{ Intensity and returns } \\
\hline & & $\beta_{1}$ & $\beta_{2}$ & $\beta_{3}$ & $\mathrm{z}_{1}$ & $\mathrm{z}_{2}$ & $\mathrm{z}_{3}$ \\
\hline & & -0.0014 & 0.0002 & -0.0001 & 0.9227 & -0.0066 & -0.0047 \\
\hline & & {$[-0.62]$} & [0.09] & {$[-0.06]$} & [39.34] & {$[-0.28]$} & {$[-0.21]$} \\
\hline & Glob. fin. crisis & -0.3243 & 0.1266 & -0.1351 & 0.0051 & 0.0249 & -0.0197 \\
\hline & & {$[-197.93]$} & [73.96] & {$[-82.43]$} & {$[1.43]$} & {$[6.91]$} & {$[-5.55]$} \\
\hline & Euro sov. debt crisis & -0.3136 & -0.1655 & -0.1282 & 0.0411 & 0.0230 & 0.0232 \\
\hline & & {$[-248.6]$} & {$[-126.7]$} & {$[-101.61]$} & {$[6.05]$} & {$[3.38]$} & [3.5] \\
\hline \multirow[t]{6}{*}{ France } & Calm & 0.1582 & -0.0251 & 0.0037 & -0.2311 & 0.0381 & -0.0049 \\
\hline & & [69.29] & {$[-10.86]$} & [1.62] & {$[-21.87]$} & [3.6] & {$[-0.47]$} \\
\hline & Glob. fin. crisis & -0.0240 & 0.0029 & -0.0024 & 0.0057 & -0.0007 & 0.0006 \\
\hline & & {$[-13.36]$} & {$[1.63]$} & {$[-1.34]$} & {$[5.3]$} & {$[-0.68]$} & {$[0.51]$} \\
\hline & Euro sov. debt crisis & 0.0409 & 0.0375 & 0.0192 & -0.0552 & -0.0072 & -0.0086 \\
\hline & & [32.95] & [30.19] & {$[15.51]$} & {$[-14.51]$} & {$[-1.89]$} & {$[-2.27]$} \\
\hline \multirow[t]{6}{*}{ Italy } & Calm & -0.0001 & -0.0002 & -0.0001 & -0.0001 & -0.0001 & 0.0000 \\
\hline & & {$[-0.03]$} & {$[-0.09]$} & {$[-0.04]$} & {$[-0.04]$} & {$[-0.03]$} & {$[0.02]$} \\
\hline & Glob. fin. crisis & -0.0048 & -0.3555 & -0.0040 & 0.0011 & 0.0826 & 0.0009 \\
\hline & & {$[-2.84]$} & {$[-227.19]$} & {$[-2.41]$} & {$[0.99]$} & [74.55] & {$[0.78]$} \\
\hline & Euro sov. debt crisis & -0.1861 & -0.0806 & -0.0765 & -0.0758 & -0.0134 & -0.0361 \\
\hline & & {$[-122.59]$} & {$[-52.43]$} & {$[-51.27]$} & {$[-75.6]$} & {$[-13.24]$} & {$[-35.87]$} \\
\hline \multirow[t]{6}{*}{ Spain } & Calm & -0.0090 & 0.0053 & -0.0082 & 0.0073 & 0.0007 & 0.0164 \\
\hline & & {$[-4.17]$} & {$[2.48]$} & {$[-3.82]$} & {$[2.69]$} & {$[0.26]$} & {$[6.13]$} \\
\hline & Glob. fin. crisis & -0.0140 & 0.0130 & -0.0122 & 0.0294 & -0.0103 & -0.0213 \\
\hline & & {$[-8.89]$} & {$[8.29]$} & {$[-7.77]$} & [1.47] & {$[-0.51]$} & {$[-1.08]$} \\
\hline & Euro sov. debt crisis & -0.0495 & -0.0516 & 0.0536 & -0.0494 & -0.0243 & -0.0194 \\
\hline & & {$[-36.29]$} & {$[-37.81]$} & {$[39.3]$} & {$[-23.58]$} & [-11.62] & {$[-9.24]$} \\
\hline \multirow[t]{6}{*}{ Greece } & Calm & -0.0308 & 0.0098 & -0.0054 & 0.0047 & -0.0004 & -0.0043 \\
\hline & & {$[-14.15]$} & [4.49] & {$[-2.46]$} & {$[1.5]$} & {$[-0.13]$} & [-1.39] \\
\hline & Glob. fin. crisis & -0.0049 & -0.0026 & -0.0059 & -0.0288 & -0.0137 & -0.0066 \\
\hline & & {$[-2.79]$} & {$[-1.46]$} & {$[-3.36]$} & {$[-2.02]$} & {$[-0.96]$} & {$[-0.47]$} \\
\hline & Euro sov. debt crisis & -0.1993 & -0.0415 & -0.0667 & 0.0130 & 0.0099 & 0.0052 \\
\hline & & {$[-107.56]$} & {$[-21.99]$} & {$[-36.01]$} & [12.06] & {$[9.18]$} & {$[4.84]$} \\
\hline \multirow[t]{6}{*}{ Ireland } & Calm & -0.0329 & 0.0048 & 0.0015 & 0.0080 & 0.0240 & -0.0227 \\
\hline & & {$[-13.21]$} & [1.92] & {$[0.6]$} & {$[0.94]$} & {$[2.85]$} & {$[-2.74]$} \\
\hline & Glob. fin. crisis & -0.7067 & -0.4570 & -0.2279 & 0.0798 & 0.0056 & -0.0008 \\
\hline & & {$[-410.81]$} & {$[-232.4]$} & {$[-132.5]$} & {$[5.7]$} & {$[0.4]$} & {$[-0.05]$} \\
\hline & Euro sov. debt crisis & -0.0657 & 0.0071 & -0.0225 & -0.0376 & -0.0051 & -0.0299 \\
\hline & & {$[-42.21]$} & [4.55] & {$[-14.47]$} & {$[-6.46]$} & {$[-0.87]$} & {$[-5.14]$} \\
\hline \multirow[t]{6}{*}{ Portugal } & Calm & 0.0008 & -0.0015 & -0.0007 & 0.0099 & 0.0041 & 0.0075 \\
\hline & & {$[0.35]$} & {$[-0.67]$} & {$[-0.3]$} & {$[0.62]$} & {$[0.26]$} & {$[0.47]$} \\
\hline & Glob. fin. crisis & -0.2216 & 0.1823 & -0.1538 & 0.0371 & -0.0305 & 0.0221 \\
\hline & & {$[-129.63]$} & {$[105.78]$} & {$[-89.86]$} & [13.52] & [-11.13] & [8.09] \\
\hline & Euro sov. debt crisis & -0.0169 & -0.0306 & -0.0016 & -0.0126 & -0.0012 & 0.0054 \\
\hline & & {$[-11.48]$} & {$[-20.79]$} & {$[-1.08]$} & {$[-1.97]$} & {$[-0.18]$} & {$[0.84]$} \\
\hline
\end{tabular}


Panel C: Returns equation: intensity and signed trade quantities, and intercept

\begin{tabular}{|c|c|c|c|c|c|c|}
\hline \multirow{8}{*}{ Germany } & \multirow{4}{*}{ Calm } & \multicolumn{4}{|c|}{ Intensity and signed trade quantities } & \multirow{2}{*}{$\begin{array}{c}\text { Intercept } \\
\alpha\end{array}$} \\
\hline & & $\tau_{0}$ & $\tau_{1}$ & $\tau_{2}$ & $\tau_{3}$ & \\
\hline & & 0.0122 & 0.0430 & 0.0001 & -0.0475 & -0.0183 \\
\hline & & {$[1.16]$} & {$[3.94]$} & {$[0.01]$} & {$[-0.48]$} & {$[-0.9]$} \\
\hline & Glob. fin. crisis & 0.0120 & 0.0065 & -0.0026 & -0.0006 & 0.0080 \\
\hline & & [5.77] & {$[3.11]$} & {$[-1.25]$} & {$[-0.04]$} & {$[2.72]$} \\
\hline & Euro sov. debt crisis & 0.0233 & 0.0127 & 0.0041 & 0.0050 & 0.0063 \\
\hline & & [4.10] & {$[2.17]$} & {$[0.71]$} & [0.19] & {$[1.52]$} \\
\hline \multirow[t]{6}{*}{ France } & Calm & 0.0574 & -0.2831 & -0.0200 & 0.0282 & -0.2727 \\
\hline & & {$[1.52]$} & {$[-7.49]$} & {$[-0.53]$} & {$[0.10]$} & {$[-3.54]$} \\
\hline & Glob. fin. crisis & 0.0680 & 0.0661 & 0.0053 & -0.0004 & -0.0710 \\
\hline & & {$[3.98]$} & {$[3.87]$} & {$[0.31]$} & {$[0.00]$} & {$[-2.26]$} \\
\hline & Euro sov. debt crisis & 0.0042 & 0.0143 & 0.0055 & -0.0034 & 0.0022 \\
\hline & & {$[1.48]$} & {$[5.06]$} & [1.94] & {$[-0.16]$} & {$[0.5]$} \\
\hline \multirow[t]{6}{*}{ Italy } & Calm & 0.0888 & -0.0094 & 0.0068 & 0.0388 & -0.4108 \\
\hline & & [4.93] & {$[-0.52]$} & {$[0.38]$} & {$[0.51]$} & {$[-4.96]$} \\
\hline & Glob. fin. crisis & -0.0005 & 0.0039 & -0.0085 & -0.0204 & -0.0358 \\
\hline & & {$[-0.05]$} & {$[0.42]$} & {$[-0.91]$} & {$[-0.42]$} & {$[-1.26]$} \\
\hline & Euro sov. debt crisis & 0.0096 & 0.0104 & 0.0066 & -0.0230 & 0.0017 \\
\hline & & [6.36] & {$[6.86]$} & {$[4.37]$} & {$[-2.66]$} & {$[0.33]$} \\
\hline \multirow[t]{6}{*}{ Spain } & Calm & 0.0077 & 0.0028 & 0.0002 & 0.0083 & -0.0022 \\
\hline & & [8.17] & {$[2.89]$} & {$[0.16]$} & [1.24] & {$[-1.00]$} \\
\hline & Glob. fin. crisis & 0.0053 & 0.0021 & 0.0010 & -0.0029 & -0.0081 \\
\hline & & {$[0.85]$} & {$[0.33]$} & {$[0.15]$} & {$[-0.08]$} & {$[-0.69]$} \\
\hline & Euro sov. debt crisis & 0.0004 & 0.0153 & 0.0071 & -0.0115 & -0.0051 \\
\hline & & {$[0.05]$} & {$[2.12]$} & {$[0.99]$} & {$[-0.22]$} & {$[-0.34]$} \\
\hline \multirow[t]{6}{*}{ Greece } & Calm & 0.0019 & -0.0002 & -0.0015 & 0.0011 & -0.0027 \\
\hline & & [1.86] & {$[-0.19]$} & {$[-1.52]$} & {$[0.17]$} & {$[-1.10]$} \\
\hline & Glob. fin. crisis & 0.0078 & 0.0067 & 0.0038 & -0.0113 & 0.0231 \\
\hline & & {$[0.55]$} & {$[0.47]$} & {$[0.26]$} & {$[-0.15]$} & {$[1.08]$} \\
\hline & Euro sov. debt crisis & 0.3449 & 0.0566 & 0.0017 & -0.1545 & -0.0275 \\
\hline & & [12.73] & {$[2.08]$} & {$[0.06]$} & {$[-0.83]$} & {$[-0.94]$} \\
\hline \multirow[t]{6}{*}{ Ireland } & Calm & 0.0049 & 0.0014 & -0.0012 & -0.0175 & -0.0037 \\
\hline & & {$[2.68]$} & {$[0.74]$} & {$[-0.64]$} & {$[-0.89]$} & {$[-1.35]$} \\
\hline & Glob. fin. crisis & 0.0230 & 0.0071 & 0.0058 & -0.0146 & 0.0058 \\
\hline & & [1.11] & {$[0.34]$} & {$[0.28]$} & {$[-0.17]$} & {$[0.24]$} \\
\hline & Euro sov. debt crisis & 0.0287 & 0.0670 & -0.0721 & -0.0411 & -0.0669 \\
\hline & & {$[0.41]$} & {$[0.97]$} & {$[-1.01]$} & {$[-0.05]$} & {$[-1.47]$} \\
\hline \multirow[t]{6}{*}{ Portugal } & Calm & 0.0031 & 0.0003 & -0.0003 & 0.0100 & 0.0169 \\
\hline & & [1.03] & {$[0.08]$} & {$[-0.09]$} & {$[0.59]$} & {$[1.55]$} \\
\hline & Glob. fin. crisis & 0.0062 & 0.0001 & 0.0010 & -0.0108 & 0.0043 \\
\hline & & {$[4.85]$} & {$[0.10]$} & {$[0.75]$} & {$[-1.48]$} & {$[1.32]$} \\
\hline & Euro sov. debt crisis & 0.0435 & 0.0346 & 0.0287 & -0.0166 & -0.0429 \\
\hline & & {$[1.23]$} & {$[0.98]$} & {$[0.81]$} & {$[-0.07]$} & {$[-0.73]$} \\
\hline
\end{tabular}

Notes: The table displays coefficients and T-statistics for the returns equation. $\mathrm{T}$-statistics are shown in parentheses below the coefficient values. The dependent variable $r_{t}=10,000 \ln \left(P_{t} / P_{t-1}\right)$ is the change in the natural logarithm of the quoted prices; $\mathrm{T}_{t}$ is the time interval between two consecutive trades in seconds; $Q_{t}$ is the signed trade quantity in millions; $D_{t}$ is a dummy variable for the market indicator where 1 indicates a trade on the EuroMTS platform. Equation: $\mathrm{r}_{\mathrm{t}}=\bar{\alpha}^{\mathrm{r}}+\sum_{\mathrm{i}=1}^{K}\left(\bar{\beta}_{\mathrm{i}}^{\mathrm{r}}+\overline{\mathrm{z}}_{\mathrm{i}}^{\mathrm{r}} \ln \left(\mathrm{T}_{\mathrm{t}-\mathrm{i}}\right)\right) \mathrm{r}_{\mathrm{t}-\mathrm{i}}+$ $\sum_{\mathrm{i}=0}^{K}\left(\bar{\gamma}_{\mathrm{i}}^{\mathrm{r}}+\bar{\delta}_{\mathrm{i}}^{\mathrm{r}} \mathrm{D}_{\mathrm{t}-\mathrm{i}}+\bar{\tau}_{\mathrm{i}}^{\mathrm{r}} \ln \left(\mathrm{T}_{\mathrm{t}-\mathrm{i}}\right)\right) \mathrm{Q}_{\mathrm{t}-\mathrm{i}}+\varepsilon_{1, \mathrm{t}}$, lags are truncated at $K=3$ in the estimation. 
Figure 1. Monthly transactions, long benchmarks

Panel A: Time series charts
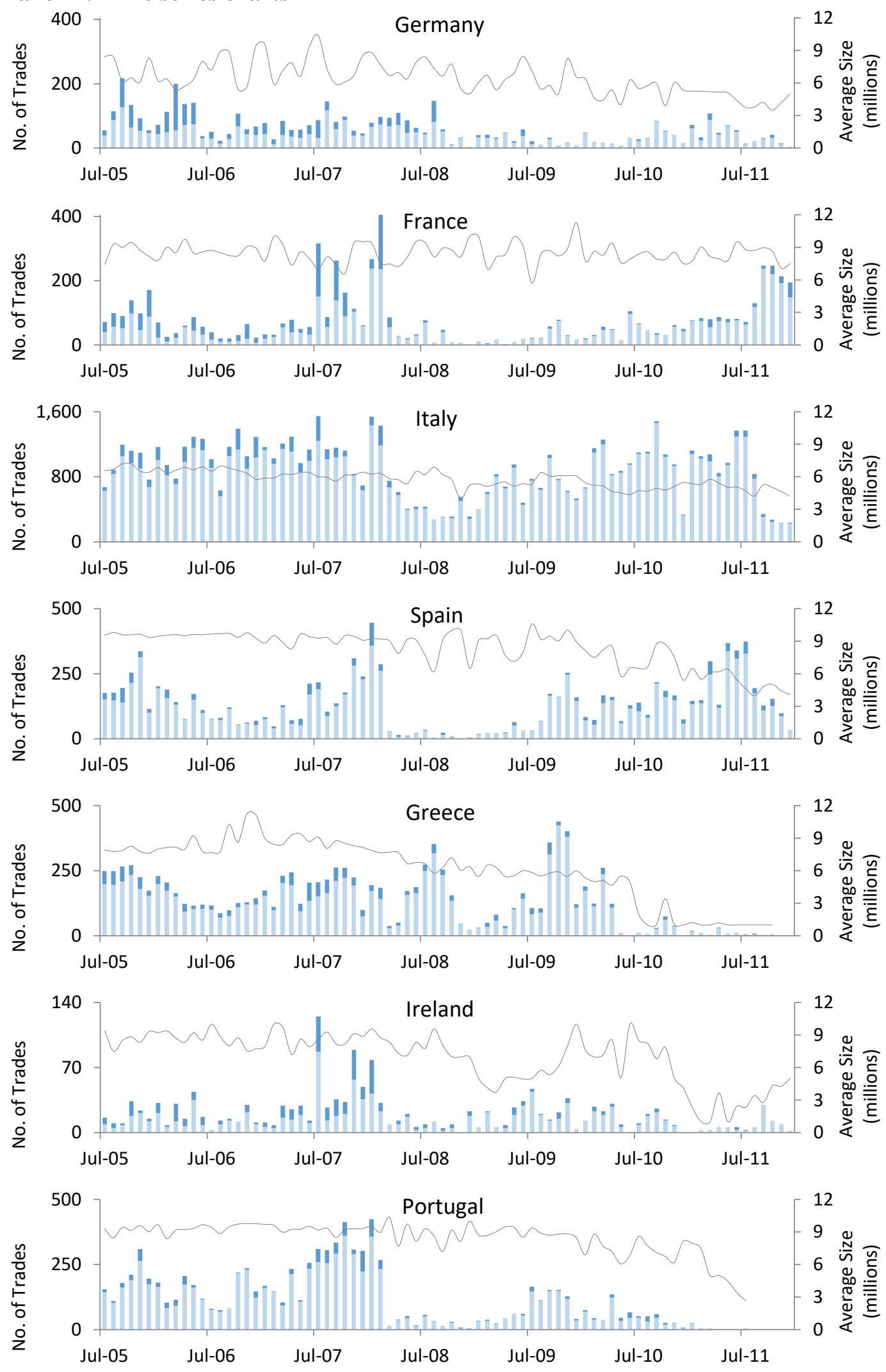
Panel B: Means and mean differences for the number of transactions

\begin{tabular}{|c|c|c|c|c|}
\hline Country & Variable & Calm & Global fin. crisis & Euro sov. debt crisis \\
\hline \multirow[t]{3}{*}{ Germany } & Mean & 87.7 & 56.4 & 37.8 \\
\hline & t-stat & & 2.557 & 2.033 \\
\hline & p-value & & 0.007 & 0.024 \\
\hline \multirow[t]{3}{*}{ France } & Mean & 63.6 & 75.5 & 90.2 \\
\hline & t-stat & & -0.530 & -0.610 \\
\hline & p-value & & 0.299 & 0.272 \\
\hline \multirow[t]{3}{*}{ Italy } & Mean & $1,068.1$ & 754.5 & 897.0 \\
\hline & t-stat & & 3.711 & -1.429 \\
\hline & p-value & & $<0.001$ & 0.079 \\
\hline \multirow[t]{3}{*}{ Spain } & Mean & 131.3 & 107.2 & 165.4 \\
\hline & t-stat & & 0.884 & -2.019 \\
\hline & p-value & & 0.190 & 0.024 \\
\hline \multirow[t]{3}{*}{ Greece } & Mean & 172.5 & 174.0 & 41.1 \\
\hline & t-stat & & -0.058 & 5.095 \\
\hline & p-value & & 0.477 & $<0.001$ \\
\hline \multirow[t]{3}{*}{ Ireland } & Mean & 19.2 & 27.7 & 11.3 \\
\hline & t-stat & & -1.283 & 2.672 \\
\hline & $\mathrm{p}$-value & & 0.103 & 0.005 \\
\hline \multirow[t]{3}{*}{ Portugal } & Mean & 159.1 & 135.4 & 27.6 \\
\hline & t-stat & & 0.795 & 3.857 \\
\hline & p-value & & 0.215 & $<0.001$ \\
\hline
\end{tabular}

Notes: In Panel A the graphs display monthly number of transactions and average transaction size for the long benchmark instruments. Light blue indicates the transactions on the MTS Domestic Markets segment, dark blue the EuroMTS segment. Panel B displays the mean number of transactions for each of the three periods, and the mean differences between the number of transactions in the first and second, and second and third periods. The panel displays coefficients, $t$-statistics and $P$-values; bold indicates significant at the $5 \%$ level. 
Table 3. Impact of a trade on the quoted price

\begin{tabular}{|c|c|c|c|}
\hline & & $\begin{array}{r}\text { MTS Domestic } \\
\text { Markets }\end{array}$ & EuroMTS \\
\hline \multirow[t]{3}{*}{ Germany } & Calm & 0.197 & 0.206 \\
\hline & Glob fin. crisis & 0.143 & -0.028 \\
\hline & Euro sov. debt crisis & 0.114 & 0.127 \\
\hline \multirow[t]{3}{*}{ France } & Calm & -2.409 & 0.689 \\
\hline & Glob fin. crisis & 0.838 & 0.012 \\
\hline & Euro sov. debt crisis & 0.377 & 0.854 \\
\hline \multirow[t]{3}{*}{ Italy } & Calm & -1.088 & -0.638 \\
\hline & Glob fin. crisis & 0.057 & 0.044 \\
\hline & Euro sov. debt crisis & 0.233 & 0.260 \\
\hline \multirow[t]{3}{*}{ Spain } & Calm & 0.054 & 0.129 \\
\hline & Glob fin. crisis & -0.011 & 0.076 \\
\hline & Euro sov. debt crisis & 0.742 & 1.455 \\
\hline \multirow[t]{3}{*}{ Greece } & Calm & 0.189 & 0.134 \\
\hline & Glob fin. crisis & 0.254 & 0.283 \\
\hline & Euro sov. debt crisis & -0.994 & 2.062 \\
\hline \multirow[t]{3}{*}{ Ireland } & Calm & 0.063 & -0.093 \\
\hline & Glob fin. crisis & 0.094 & -0.275 \\
\hline & Euro sov. debt crisis & 3.932 & 4.385 \\
\hline \multirow[t]{3}{*}{ Portugal } & Calm & 0.037 & 0.021 \\
\hline & Glob fin. crisis & -0.025 & -0.011 \\
\hline & Euro sov. debt crisis & -0.145 & 4.777 \\
\hline
\end{tabular}

Notes: This table displays the estimated impact, in basis points, on the quoted price following a five million euro trade. 
Table 4. Quantities equation

Panel A: Quantities equation: trade quantity, and market and trade quantity

\begin{tabular}{|c|c|c|c|c|c|c|c|}
\hline \multirow{8}{*}{ Germany } & \multirow{4}{*}{ Calm } & \multicolumn{3}{|c|}{ Lagged trade quantities } & \multicolumn{3}{|c|}{ Market and lagged trade quantities } \\
\hline & & $\gamma_{1}$ & $\gamma_{2}$ & $\gamma_{3}$ & $\delta_{1}$ & $\delta_{2}$ & $\delta_{3}$ \\
\hline & & 0.1419 & 0.0284 & 0.0276 & -0.0527 & 0.0084 & -0.0138 \\
\hline & & [31.18] & [6.15] & {$[8.94]$} & {$[-11.62]$} & {$[1.86]$} & {$[-3.06]$} \\
\hline & Glob. fin. crisis & 0.0753 & 0.0739 & 0.0264 & -0.0328 & -0.0012 & -0.0096 \\
\hline & & [21.83] & {$[21.31]$} & [12.26] & {$[-9.45]$} & {$[-0.36]$} & {$[-2.75]$} \\
\hline & Euro sov. debt crisis & 0.1891 & 0.1178 & 0.0377 & -0.0215 & -0.0045 & 0.0173 \\
\hline & & {$[80.62]$} & [49.77] & [26.28] & {$[-5.37]$} & {$[-1.12]$} & {$[4.34]$} \\
\hline \multirow[t]{6}{*}{ France } & Calm & 0.1266 & 0.0897 & 0.0637 & -0.0058 & -0.0249 & -0.0415 \\
\hline & & [32.72] & [22.99] & [22.59] & {$[-1.26]$} & {$[-5.37]$} & {$[-9.31]$} \\
\hline & Glob. fin. crisis & 0.1642 & 0.0341 & 0.0225 & 0.0208 & 0.1693 & 0.0359 \\
\hline & & [51.93] & {$[10.72]$} & [11.61] & {$[4.87]$} & [39.85] & {$[8.51]$} \\
\hline & Euro sov. debt crisis & 0.1355 & 0.0720 & 0.0320 & 0.0766 & 0.0089 & 0.0164 \\
\hline & & [55.52] & {$[29.08]$} & [22.71] & [12.39] & {$[1.43]$} & {$[2.65]$} \\
\hline \multirow{6}{*}{ Italy } & Calm & 0.1366 & 0.0601 & 0.0415 & 0.0202 & 0.0111 & 0.0281 \\
\hline & & [36.96] & [16.19] & [16.46] & [3.29] & {$[1.81]$} & [4.57] \\
\hline & Glob. fin. crisis & 0.1408 & 0.0838 & 0.0437 & 0.0387 & 0.0066 & 0.0223 \\
\hline & & [49.19] & [29.13] & [23.49] & {$[7.35]$} & {$[1.25]$} & {$[4.24]$} \\
\hline & Euro sov. debt crisis & 0.1067 & 0.0521 & 0.0190 & 0.0746 & 0.0205 & 0.0414 \\
\hline & & [36.89] & [17.89] & [11.84] & {$[7.53]$} & {$[2.06]$} & {$[4.18]$} \\
\hline \multirow[t]{6}{*}{ Spain } & Calm & 0.1159 & 0.0621 & 0.0234 & 0.0758 & 0.0021 & -0.0046 \\
\hline & & [26.57] & {$[14.03]$} & {$[9.74]$} & [11.59] & {$[0.33]$} & {$[-0.7]$} \\
\hline & Glob. fin. crisis & 0.2337 & 0.1363 & 0.0325 & 0.0178 & -0.0197 & 0.0186 \\
\hline & & [79.09] & {$[45.47]$} & [18.09] & {$[3.76]$} & {$[-4.16]$} & [3.92] \\
\hline & Euro sov. debt crisis & 0.0987 & 0.0476 & 0.0132 & 0.0064 & 0.0382 & 0.0175 \\
\hline & & [34.07] & [16.29] & {$[9.23]$} & {$[0.91]$} & {$[5.43]$} & {$[2.48]$} \\
\hline \multirow[t]{6}{*}{ Greece } & Calm & 0.0788 & 0.0599 & 0.0085 & 0.0156 & -0.0062 & -0.0035 \\
\hline & & [15.47] & [11.62] & {$[3.30]$} & {$[2.78]$} & {$[-1.11]$} & {$[-0.62]$} \\
\hline & Glob. fin. crisis & 0.0816 & 0.0496 & 0.0162 & -0.0167 & -0.0313 & 0.0022 \\
\hline & & [20.93] & {$[12.65]$} & {$[8.00]$} & {$[-3.71]$} & {$[-6.94]$} & {$[0.49]$} \\
\hline & Euro sov. debt crisis & 0.1140 & 0.0721 & 0.0266 & 0.0651 & 0.0231 & -0.0007 \\
\hline & & [35.82] & [22.27] & {$[13.7]$} & {$[10.35]$} & [3.67] & {$[-0.11]$} \\
\hline \multirow[t]{6}{*}{ Ireland } & Calm & 0.2180 & -0.0202 & 0.0187 & 0.0191 & 0.0556 & -0.0352 \\
\hline & & [41.93] & {$[-3.77]$} & {$[5.64]$} & [3.67] & {$[10.72]$} & {$[-6.78]$} \\
\hline & Glob. fin. crisis & 0.2324 & 0.1002 & 0.0334 & -0.0134 & -0.0116 & -0.0168 \\
\hline & & [69.53] & [29.7] & {$[13.66]$} & {$[-3.79]$} & {$[-3.26]$} & {$[-4.77]$} \\
\hline & Euro sov. debt crisis & 0.1302 & 0.0617 & 0.0249 & 0.1020 & -0.0509 & 0.0683 \\
\hline & & [35.61] & {$[16.14]$} & [14.12] & {$[20.03]$} & {$[-9.97]$} & {$[13.34]$} \\
\hline \multirow{6}{*}{ Portugal } & Calm & 0.1547 & 0.0599 & 0.0559 & -0.0318 & -0.0079 & 0.0043 \\
\hline & & [33.88] & [12.99] & [18.73] & {$[-3.97]$} & {$[-0.99]$} & {$[0.53]$} \\
\hline & Glob. fin. crisis & 0.2015 & 0.1059 & 0.0527 & -0.0256 & 0.0435 & 0.0069 \\
\hline & & [62.79] & [32.72] & [24.76] & {$[-5.87]$} & [9.99] & {$[1.58]$} \\
\hline & Euro sov. debt crisis & 0.1478 & 0.0553 & 0.0169 & 0.0390 & 0.0272 & 0.0701 \\
\hline & & [48.49] & {$[17.96]$} & {$[10.41]$} & {$[5.45]$} & {$[3.8]$} & {$[9.8]$} \\
\hline
\end{tabular}


Panel B: Quantities equation: returns, and intensity and returns

\begin{tabular}{|c|c|c|c|c|c|c|c|}
\hline \multirow{4}{*}{ Germany } & \multirow{4}{*}{ Calm } & \multicolumn{3}{|c|}{ Lagged returns } & \multicolumn{3}{|c|}{ Intensity and lagged returns } \\
\hline & & \multirow{3}{*}{$\begin{array}{c}\beta_{1} \\
0.0001 \\
{[0.34]}\end{array}$} & \multirow{3}{*}{$\begin{array}{c}\beta_{2} \\
0.0001 \\
{[0.26]}\end{array}$} & \multirow{3}{*}{$\begin{array}{c}\beta_{3} \\
-0.0000 \\
{[-0.02]}\end{array}$} & \multirow{3}{*}{$\begin{array}{c}\mathrm{Z}_{1} \\
-0.0259 \\
{[-\mathbf{- 1 1 . 6 8}]}\end{array}$} & \multirow{3}{*}{$\begin{array}{c}\mathrm{z}_{2} \\
-0.0006 \\
{[-0.28]}\end{array}$} & \multirow{3}{*}{$\begin{array}{c}\mathrm{z}_{3} \\
-0.0045 \\
{[-\mathbf{- 2 . 0 8}]}\end{array}$} \\
\hline & & & & & & & \\
\hline & & & & & & & \\
\hline & \multirow[t]{2}{*}{ Glob. fin. crisis } & 0.0006 & 0.0010 & 0.0001 & -0.0103 & -0.0000 & -0.0039 \\
\hline & & {$[1.01]$} & {$[1.62]$} & {$[0.16]$} & {$[-7.74]$} & {$[-0.03]$} & {$[-2.93]$} \\
\hline & \multirow[t]{2}{*}{ Euro sov. debt crisis } & -0.0001 & -0.0001 & -0.0001 & -0.0129 & -0.0027 & -0.0029 \\
\hline & & {$[-1.08]$} & {$[-1.03]$} & {$[-0.79]$} & {$[-20.58]$} & {$[-4.25]$} & {$[-4.68]$} \\
\hline \multirow[t]{6}{*}{ France } & \multirow[t]{2}{*}{ Calm } & 0.0000 & 0.0000 & 0.0000 & -0.0005 & -0.0002 & -0.0002 \\
\hline & & {$[0.66]$} & {$[0.37]$} & {$[0.28]$} & {$[-1.83]$} & {$[-0.76]$} & {$[-0.68]$} \\
\hline & \multirow[t]{2}{*}{ Glob. fin. crisis } & -0.0001 & -0.0000 & -0.0000 & -0.0001 & -0.0000 & -0.0000 \\
\hline & & {$[-1.3]$} & {$[-0.58]$} & {$[-0.05]$} & {$[-2.06]$} & {$[-0.68]$} & {$[-0.5]$} \\
\hline & \multirow[t]{2}{*}{ Euro sov. debt crisis } & -0.0012 & -0.0009 & -0.0001 & -0.0096 & -0.0058 & 0.0025 \\
\hline & & {$[-4.8]$} & {$[-3.31]$} & {$[-0.57]$} & {$[-12.21]$} & {$[-7.43]$} & [3.23] \\
\hline \multirow[t]{6}{*}{ Italy } & \multirow[t]{2}{*}{ Calm } & 0.0001 & -0.0002 & -0.0001 & -0.0001 & 0.0000 & 0.0001 \\
\hline & & {$[0.65]$} & {$[-1.18]$} & {$[-0.28]$} & {$[-0.47]$} & {$[0.31]$} & {$[0.9]$} \\
\hline & \multirow[t]{2}{*}{ Glob. fin. crisis } & -0.0001 & -0.0000 & -0.0001 & 0.0000 & 0.0000 & 0.0000 \\
\hline & & {$[-0.64]$} & {$[-0.24]$} & {$[-0.35]$} & {$[0.03]$} & {$[0.04]$} & [0.09] \\
\hline & \multirow[t]{2}{*}{ Euro sov. debt crisis } & -0.0066 & -0.0038 & -0.0007 & -0.0005 & 0.0000 & -0.0007 \\
\hline & & {$[-6.34]$} & {$[-3.62]$} & {$[-0.73]$} & {$[-0.72]$} & {$[0.06]$} & {$[-0.97]$} \\
\hline \multirow[t]{6}{*}{ Spain } & \multirow[t]{2}{*}{ Calm } & -0.0008 & -0.0034 & 0.0021 & -0.0267 & -0.0067 & -0.0126 \\
\hline & & {$[-0.31]$} & {$[-1.28]$} & {$[0.81]$} & [-7.99] & {$[-1.99]$} & {$[-3.81]$} \\
\hline & \multirow[t]{2}{*}{ Glob. fin. crisis } & -0.0000 & -0.0001 & -0.0000 & -0.0134 & -0.0069 & -0.0062 \\
\hline & & {$[-0.18]$} & {$[-0.28]$} & {$[-0.05]$} & {$[-5.17]$} & {$[-2.66]$} & {$[-2.41]$} \\
\hline & Euro sov. debt crisis & -0.0003 & -0.0002 & -0.0001 & -0.0003 & 0.0003 & 0.0001 \\
\hline & & [-1.98] & {$[-1.28]$} & {$[-0.99]$} & [-1.49] & {$[1.48]$} & {$[0.66]$} \\
\hline Greece & Calm & -0.0113 & -0.0038 & 0.0027 & -0.0202 & -0.0063 & -0.0008 \\
\hline & & {$[-3.89]$} & {$[-1.3]$} & {$[0.92]$} & {$[-4.81]$} & {$[-1.5]$} & {$[-0.19]$} \\
\hline & Glob. fin. crisis & -0.0001 & -0.0000 & 0.0000 & -0.0065 & -0.0047 & -0.0028 \\
\hline & & {$[-0.73]$} & {$[-0.33]$} & {$[0.06]$} & {$[-6.03]$} & {$[-4.43]$} & {$[-2.65]$} \\
\hline & Euro sov. debt crisis & -0.0002 & -0.0001 & -0.0001 & -0.0001 & -0.0000 & -0.0000 \\
\hline & & {$[-2.18]$} & {$[-1.35]$} & {$[-1.1]$} & {$[-2.93]$} & {$[-0.42]$} & {$[-0.16]$} \\
\hline Ireland & Calm & -0.0003 & -0.0003 & -0.0000 & -0.0612 & 0.0259 & 0.0020 \\
\hline & & {$[-0.21]$} & {$[-0.23]$} & {$[-0.01]$} & {$[-14.03]$} & {$[5.93]$} & {$[0.46]$} \\
\hline & Glob. fin. crisis & -0.0000 & -0.0000 & -0.0000 & -0.0040 & -0.0025 & 0.0019 \\
\hline & & {$[-0.73]$} & {$[-0.4]$} & {$[-0.3]$} & {$[-8.07]$} & {$[-5.09]$} & [3.85] \\
\hline & Euro sov. debt crisis & -0.0000 & -0.0000 & -0.0000 & -0.0005 & -0.0000 & -0.0002 \\
\hline & & {$[-1.82]$} & {$[-0.67]$} & {$[-1.10]$} & {$[-9.25]$} & {$[-0.66]$} & {$[-3.56]$} \\
\hline Portugal & Calm & -0.0008 & -0.0002 & -0.0001 & -0.0458 & 0.0048 & -0.0128 \\
\hline & & {$[-0.89]$} & {$[-0.23]$} & {$[-0.11]$} & {$[-7.00]$} & {$[0.74]$} & {$[-1.98]$} \\
\hline & Glob. fin. crisis & -0.0047 & -0.0035 & -0.0006 & -0.0111 & -0.0051 & -0.0024 \\
\hline & & {$[-3.96]$} & {$[-2.92]$} & {$[-0.47]$} & {$[-5.87]$} & {$[-2.67]$} & {$[-1.26]$} \\
\hline & Euro sov. debt crisis & -0.0000 & -0.0000 & -0.0000 & -0.0010 & -0.0003 & -0.0007 \\
\hline & & {$[-0.69]$} & {$[-0.39]$} & {$[-0.13]$} & {$[-8.21]$} & {$[-2.66]$} & {$[-5.72]$} \\
\hline
\end{tabular}


Panel C: Quantities equation: intensity and trade quantity, and intercept

\begin{tabular}{|c|c|c|c|c|c|}
\hline \multirow{8}{*}{ Germany } & \multirow{4}{*}{ Calm } & \multicolumn{3}{|c|}{ Intensity and lagged trade quantities } & \multirow{2}{*}{$\begin{array}{c}\text { Intercept } \\
\alpha \\
\end{array}$} \\
\hline & & $\tau_{1}$ & $\tau_{2}$ & $\tau_{3}$ & \\
\hline & & -0.0071 & -0.0049 & 0.00762 & -0.0006 \\
\hline & & {$[-6.85]$} & {$[-4.67]$} & {$[0.8100]$} & {$[-0.30]$} \\
\hline & Glob. fin. crisis & 0.0001 & -0.0136 & 0.00449 & -0.0050 \\
\hline & & {$[0.10]$} & {$[-17.42]$} & {$[0.9100]$} & {$[-4.51]$} \\
\hline & Euro sov. debt crisis & -0.0147 & -0.0171 & 0.03915 & 0.0006 \\
\hline & & [-27.35] & {$[-31.78]$} & {$[16.1900]$} & [1.60] \\
\hline \multirow[t]{6}{*}{ France } & Calm & -0.0064 & -0.0102 & 0.0370 & 0.0020 \\
\hline & & {$[-6.42]$} & {$[-10.27]$} & [4.74] & [0.99] \\
\hline & Glob. fin. crisis & -0.0113 & 0.0016 & -0.0083 & -0.0037 \\
\hline & & {$[-14.12]$} & {$[2.03]$} & {$[-1.75]$} & {$[-2.49]$} \\
\hline & Euro sov. debt crisis & -0.0103 & -0.0093 & -0.0081 & -0.0003 \\
\hline & & {$[-17.6]$} & {$[-15.80]$} & {$[-1.88]$} & {$[-0.36]$} \\
\hline \multirow[t]{6}{*}{ Italy } & Calm & -0.0118 & -0.0037 & -0.0119 & 0.0253 \\
\hline & & {$[-7.79]$} & {$[-2.47]$} & {$[-1.87]$} & [3.62] \\
\hline & Glob. fin. crisis & -0.0123 & -0.0099 & 0.0193 & 0.0060 \\
\hline & & [-11.95] & {$[-9.65]$} & {$[3.64]$} & [1.92] \\
\hline & Euro sov. debt crisis & -0.0140 & -0.0080 & 0.0351 & -0.0081 \\
\hline & & {$[-13.5]$} & {$[-7.68]$} & [5.97] & {$[-2.31]$} \\
\hline \multirow[t]{6}{*}{ Spain } & Calm & -0.0120 & -0.0057 & 0.0582 & 0.0080 \\
\hline & & {$[-10.06]$} & {$[-4.78]$} & {$[7.01]$} & {$[2.93]$} \\
\hline & Glob. fin. crisis & -0.0262 & -0.0158 & -0.0282 & -0.0048 \\
\hline & & [-32.23] & {$[-19.53]$} & {$[-5.88]$} & {$[-3.17]$} \\
\hline & Euro sov. debt crisis & -0.0088 & -0.0056 & -0.0021 & 0.0017 \\
\hline & & [-12.29] & {$[-7.78]$} & {$[-0.42]$} & {$[1.14]$} \\
\hline \multirow[t]{6}{*}{ Greece } & Calm & -0.0069 & -0.0108 & 0.0120 & 0.0046 \\
\hline & & {$[-5.16]$} & {$[-7.97]$} & {$[1.35]$} & [1.39] \\
\hline & Glob. fin. crisis & -0.0031 & -0.0023 & -0.0290 & -0.0015 \\
\hline & & {$[-2.91]$} & {$[-2.13]$} & {$[-5.06]$} & {$[-0.94]$} \\
\hline & Euro sov. debt crisis & -0.0081 & -0.0111 & 0.0320 & -0.0040 \\
\hline & & {$[-7.79]$} & {$[-10.6]$} & [4.5] & {$[-3.57]$} \\
\hline \multirow[t]{6}{*}{ Ireland } & Calm & -0.0197 & 0.0144 & 0.1486 & -0.0035 \\
\hline & & {$[-20.7]$} & {$[15]$} & [14.54] & {$[-2.47]$} \\
\hline & Glob. fin. crisis & -0.0094 & -0.0032 & -0.0300 & -0.0036 \\
\hline & & {$[-12.75]$} & {$[-4.4]$} & {$[-9.66]$} & {$[-4.22]$} \\
\hline & Euro sov. debt crisis & -0.0054 & -0.0066 & 0.0104 & -0.0012 \\
\hline & & {$[-8.54]$} & [-9.99] & [1.29] & {$[-2.8]$} \\
\hline \multirow[t]{6}{*}{ Portugal } & Calm & -0.0037 & 0.0031 & -0.0400 & -0.0034 \\
\hline & & {$[-3.01]$} & {$[2.57]$} & {$[-5.82]$} & {$[-0.77]$} \\
\hline & Glob. fin. crisis & -0.0118 & -0.0070 & 0.0425 & -0.0043 \\
\hline & & [-13.33] & {$[-7.91]$} & {$[8.47]$} & {$[-1.91]$} \\
\hline & Euro sov. debt crisis & 0.0027 & -0.0049 & 0.0124 & 0.0037 \\
\hline & & [4.07] & [-7.39] & {$[2.88]$} & {$[3.38]$} \\
\hline
\end{tabular}

Notes: The table displays coefficients and T-statistics for the quantities equation. T-statistics are shown in parentheses below the coefficient values. The dependent variable $r_{t}=10,000 \ln \left(\mathrm{P}_{t} / \mathrm{P}_{\mathrm{t}-1}\right)$ is the change in the natural logarithm of the quoted prices; $T_{t}$ is the time interval between two consecutive trades in seconds; $Q_{t}$ is the signed trade quantity in millions; $D_{t}$ is a dummy variable for the market indicator where 1 indicates a trade on the EuroMTS platform. Equation: $\mathrm{Q}_{\mathrm{t}}=\bar{\alpha}^{\mathrm{Q}}+\sum_{\mathrm{i}=1}^{K}\left(\bar{\beta}_{\mathrm{i}}^{\mathrm{Q}}+\right.$ $\left.\overline{\mathrm{z}}_{\mathrm{i}}^{\mathrm{Q}} \ln \left(\mathrm{T}_{\mathrm{t}-\mathrm{i}}\right)\right) \mathrm{r}_{\mathrm{t}-\mathrm{i}}+\sum_{\mathrm{i}=1}^{K}\left(\bar{\gamma}_{\mathrm{i}}^{\mathrm{Q}}+\bar{\delta}_{\mathrm{i}}^{\mathrm{Q}} \mathrm{D}_{\mathrm{t}-\mathrm{i}}+\bar{\tau}_{\mathrm{i}}^{\mathrm{Q}} \ln \left(\mathrm{T}_{\mathrm{t}-\mathrm{i}}\right)\right) \mathrm{Q}_{\mathrm{t}-\mathrm{i}}+\varepsilon_{2, \mathrm{t}}$, lags are truncated at $K=3$ in the estimation. 
